\title{
Ultrasound screening of the kidneys and urinary tract in 11,887 newborn infants: A 10-year experience
}

\author{
Susanne E. Gruessner, ${ }^{1,2 *}$, Katja Klein ${ }^{3}$, Corinna Peter ${ }^{4}$, Eva Bueltmann ${ }^{5}$, Jenny Wagner ${ }^{6}$, \\ Volker Klingmueller ${ }^{3}$ \\ ${ }^{1}$ Department of Obstetrics, Gynecology and Reproductive Medicine, Hannover Medical School, Hannover, Germany \\ ${ }^{2}$ Department of Obstetrics and Gynecology, Justus-Liebig-University of Giessen, Giessen, Germany \\ ${ }^{3}$ Department of Pediatric Radiology, University of Marburg, Marburg, Germany \\ ${ }^{4}$ Department of Pediatric Pulmonology, Allergology and Neonatology, Hannover Medical School, Hannover, Germany \\ ${ }^{5}$ Institute of Diagnostic and Interventional Neuroradiology, Hannover Medical School, Hannover, Germany \\ ${ }^{6}$ Department of Obstetrics, Vivantes Medical Centre Neukoelln, Berlin, Germany \\ Email: " gruessner.susanne@mh-hannover.de, susanne.gruessner@gmx.de
}

Received 16 August 2012; revised 15 September 2012; accepted 25 September 2012

\begin{abstract}
Objective: To determine the usefulness of sonographic screening of the newborn kidneys and urinary tract over a 10-year time period. Methods: Ultrasound screening of the kidneys and the urinary tract was performed between the third and tenth day after birth on 11.887 newborn infants. The classification of renal pyelectasis (RPE) according to the Society for Fetal Urology (SFU) was used. We evaluated infant renal pathologies and correlated them with the gestational age and weight at birth. Results: Renal pyelectasis (grades 1-4) was detected in 179 cases (1.5\%); it was significantly more common in male (vs female) infants ( $p<0.001)$. One- (vs two-) sided dilatation of the renal pelvis was more common, with the left side dominating $(p<0.05)$. Renal pyelectasis was occasionally associated with parenchymal and positional anomalies, such as nephrocalcinosis $(0.27 \%)$, double kidneys $(0.24 \%)$, horseshoe kidneys $(0.11 \%)$, pelvic kidneys $(0.08 \%)$, multicystic $(0.07 \%)$ and polycystic $(0.025 \%)$ kidneys. In infants with renal pyelectasis grade $4(n=36)$, gestational diabetes mellitus of the mother and birth weight $>4.000 \mathrm{~g}$ were the most significant risk factors $(p<0.01)$. Conclusions: Renal pyelectasis grades 1-4 was detected in only $1.5 \%$ of 11.887 consecutive infants subjected to sonographic screening of the kidneys and the urinary tract within the first 10 days after birth. Sonographic screening of the kidneys and the urinary tract is a non-invasive and effective screening method after birth. It allows planning for appropriate diagnostic tests and therapeutic procedures in a timely fashion.
\end{abstract}

Keywords: Renal Ultrasound Screening; Renal
Pyelectasis; Renal Dysplasia; Preterm Newborns

\section{INTRODUCTION}

About one third of all congenital organ dysplasias are localized in the urogenital tract [1]. Most commonly congenital renal pyelectasis is caused by stenosis of the ureteropelvic or the ureterovesical junction or by posterior urethral valves. If renal pyelectasis goes unnoticed and is not been treated in a timely fashion, severe damage of the kidney can be the result [2,3]. Early detection of these changes allows timely initiation of more specific diagnostic studies and of therapeutic interventions [4-6].

The extent of renal pyelectasis (RPE) is usually graded according to the classification of the Society for Fetal Urology (SFU) [7,8]. The purpose of this study was to determine the incidence of RPE by sonographic screening (using high-frequency and high-resolution ultrasound scanners $(5-7.5 \mathrm{MHz})[7,9])$ in a large infant population in the immediate postnatal period. Anatomical abnormalities (e.g., double kidneys, horseshoe kidneys, and dystopic kidneys) and changes in the structure of the renal parenchyma (e.g., poly- or multicystic kidney dysplasia) were also identified and documented. The purpose of this large epidemiologic study was not to document longterm outcome or therapeutic strategies in infants with RPE.

\section{MATERIAL AND METHODS}

Over a 10-year time period, we performed sonographic screening of the kidneys and the urinary tract in 11.887 newborn infants, born at the Department of Obstetrics and Gynecology (a tertiary referral centre), University of Giessen, Germany. Of those, $51.2 \%(n=6.088)$ were males and $48.8 \%(n=5.799)$ females. 
The median duration of the gestation period was 39 (range, 24 to 45$)$ weeks. In all, 18.8\% $(\mathrm{n}=2.238)$ infants were born before the 37 th gestational week (preterm infants). The incidence of post-term infants ( $\geq 41$ st gestation week) was $27 \%(n=3.221)$. The weight at birth ranged from $350 \mathrm{~g}$ to $5.600 \mathrm{~g}$, with a median value of $3.190 \mathrm{~g}$.

Sonographic screening of the kidneys and the urinary tract was performed in 11.054 single births (93.0\%), 771 twins (6.5\%) and 62 triplets (0.5\%); it was performed between the third and tenth day of life as part of the initial newborn examination at the Department of Pediatric Radiology, University of Giessen. Over the 10-year time period, we used three different ultrasound devices: 1) the Siemens Sonoline ${ }^{\circledR}$ with a $5 \mathrm{MHz}$ Sector- and Linear ultrasound scannerSi; 2) the Siemens RA- ${ }^{\circledR}$ with a 7.5 MHz Small Part ultrasound scanner; and 3) the Acuson $128 \mathrm{XP} / 10^{\circledR}$ with a $5 \mathrm{MHz}$ Linear- and Sector ultrasound scanner. To assure quality consistency, all sonographies were performed or signed out by one experienced pediatric radiologist (VK).

Sonographic findings were available in written and in photodocumented form. RPE was graded according to the SFU classification (grade 0: 1 - $5 \mathrm{~mm}$ [normal]; grade 1: 6 - $10 \mathrm{~mm}$ [dilatation of renal pelvis only]; grade 2: $11-12 \mathrm{~mm}$ [dilatation of renal pelvis and few renal calices]; grade 3: $>12 \mathrm{~mm}$ [dilatation of renal pelvis, all calices, parenchyma of normal thickness]; grade 4: $>12 \mathrm{~mm}$ [dilatation of renal pelvis, all calices, reduced thickness of parenchyma] [6].

For statistical analysis, sonographic findings were correlated with duration of gestation and weight at birth, information that was obtained from the birth books. We divided the gestation period into 4 groups (24th-30th week, 31st-37th week, 38th-41st week, 42nd-45th week) and the birth weight into 6 groups (350 - $1.000 \mathrm{~g},>1.000$ $1.500 \mathrm{~g},>1.500-2.000 \mathrm{~g},>2.000-2.500 \mathrm{~g},>2.500-$ $4.000 \mathrm{~g},>4.000-5.600 \mathrm{~g})$. Statistical calculations were done using SPSS 11.0. We used the Chi-square and Fisher's Exact-tests. The p-value was used for exploratory purposes.

\section{RESULTS}

In $1.5 \%(n=179)$ of the newborn infants, we found RPE of varying degrees (grades 1-4). Of those, $0.96 \%(\mathrm{n}=$ 114) showed involvement of only one and $0.55 \%(n=65)$ of both kidneys/urinary tracts. In infants with only one-sided findings, the left side dominated in $68.4 \%$ ( $\mathrm{n}=$ 78) $(\mathrm{p}<0.05)$. In regards to gender, 79.3\% $(\mathrm{n}=142)$ were male and $20.7 \%(\mathrm{n}=37)$ female infants $(\mathrm{p}<0.001)$. RPE was found in $1.3 \%(\mathrm{n}=29)$ of preterm and in $1.5 \%$ $(n=150)$ of mature infants $(p=0.01)$. The percentiles of RPE (grades 1-4) were not significantly higher before 37th weeks of gestation. In all, we diagnosed renal pyelectasis of varying degrees (grades 1-4) in 179 infants
(1.5\%). Of those, 78 infants (0.88\%) showed RPE with a dilatation of $\leq 10 \mathrm{~mm}$ (grade 1); 101 infants $(0.85 \%)$, renal pyelectasis with a dilatation of $\geq 11 \mathrm{~mm}$ (grades 2-4) [9]. Of the latter group, RPE was caused in $57 \%(n=58)$ by ureteropelvic obstruction, in $23 \%(n=23$, of which 3 also had an ureterocele) by ureterovesical obstruction, in $5 \%(\mathrm{n}=5)$ by posterior urethral valves, and in $3 \%(\mathrm{n}=3)$ by a pelvic kidney; in $12 \%(n=12)$ no specific morphologic abnormality was identified. RPE grade 4 was diagnosed in 36 infants, most of them being mature and postmature ( $\geq 37$ th gestational week) (Table 1).

In fact, the incidence of RPE grade 4 was highest in infants with a birth-weight of $>4.000 \mathrm{~g}(\mathrm{n}=1.015)(\mathrm{p}=$ $0.041)$. In those infants maternal gestational diabetes was also significantly more common $(4.0 \%, \mathrm{n}=41 / 1.015)$ than in infants with a lower birth-weight $(1.4 \%, \mathrm{n}=$ 155/10.872) ( $<<0.001)$. Moreover, mature infants of mothers with gestational diabetes mellitus had a higher incidence of additional pathological findings when compared with infants of mothers without gestational diabetes mellitus $(10.1 \%, \mathrm{n}=15$ versus $4.5 \%, \mathrm{n}=422 ; \mathrm{p}=$ 0.001). RPE was also associated with anomalies in renal position and parenchyma. Anomalies in renal position included horseshoe kidneys in $13(0.11 \%)$ and pelvic kidneys in 9 infants $(0.08 \%)$. Newborn infants with horseshoe kidneys showed significantly more often RPE grade 4 ( $p=0.037)$. Likewise, infants with pelvic kidneys were significantly $(\mathrm{p}<0.001)$ more often diagnosed with RPE grade 4. Infants with cystic anomalies of the renal parenchyma showed the following findings: multicystic kidneys $(0.07 \%, \mathrm{n}=8)$, polycystic kidneys $(0.025 \%, \mathrm{n}=3)$, and single kidney-cysts $(0.025 \%, \mathrm{n}=3)$. Nephrocalcinosis was noted in 32 newborn infants (0.27\%) (Figure 1).

\section{DISCUSSION}

In our 10-year newborn-screening study of the kidneys

Table 1. Grading of renal pyelectasis (RPE), week (wk) of gestation and total numbers of examined newborns.

\begin{tabular}{cccccc}
\hline \multicolumn{5}{c}{ Renal pyelectasis and week of gestation } \\
\hline $\begin{array}{c}\text { RPE } \\
\text { grading }\end{array}$ & $\begin{array}{c}24-30 \\
\text { wk (n) }\end{array}$ & $\begin{array}{c}31-37 \\
\text { wk (n) }\end{array}$ & $\begin{array}{c}38-41 \\
\text { wk (n) }\end{array}$ & $\begin{array}{c}42-45 \\
\text { wk (n) }\end{array}$ & $\begin{array}{c}\text { Number } \\
\text { of patients } \\
\text { (n) }\end{array}$ \\
\hline Grade 0 & 9 & 98 & 268 & 16 & 391 \\
Grade 1 & 0 & 0 & 78 & 0 & 78 \\
Grade 2 & 0 & 18 & 0 & 9 & 27 \\
Grade 3 & 0 & 10 & 25 & 3 & 38 \\
Grade 4 & 0 & 1 & 33 & 2 & 36 \\
${ }^{*}$ n total & 301 & 1937 & 8859 & 790 & 570 \\
\hline
\end{tabular}

${ }^{*} \mathrm{n}$ total: number of examined newborns in individual week of gestation. 

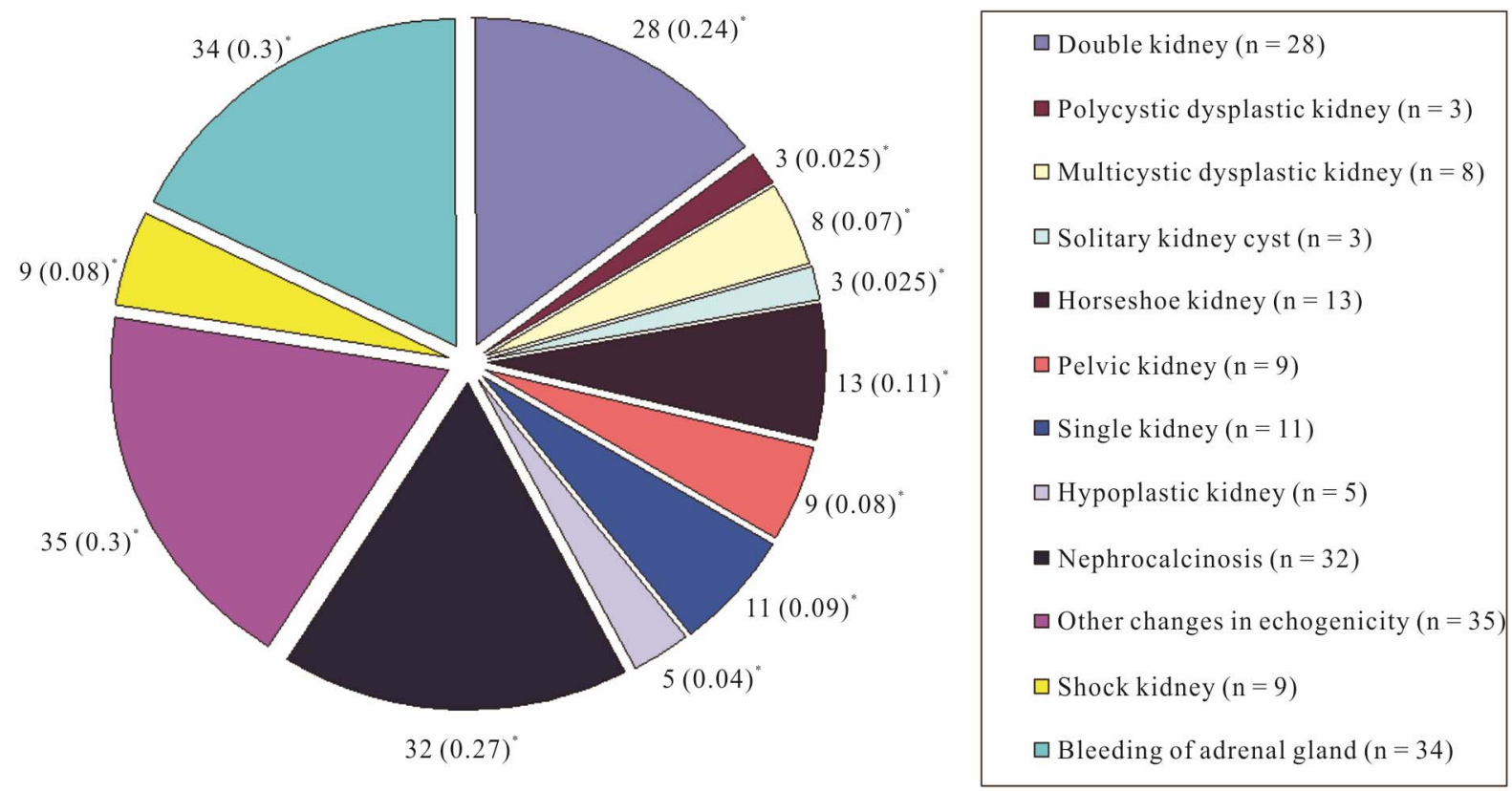

Figure 1. Distribution of anomalies in renal position and parenchyma. ${ }^{*}()=\%$ of the complete collective.

and the urinary tract, 179 of 11,887 (1.5\%) infants were diagnosed with RPE. Of those, 74 infants (0.62\%) showed RPE of $>12 \mathrm{~mm}$ (grades 3-4) and/or additional anomalies in renal parenchyma and position. RPE of $\leq 12$ $\mathrm{mm}$ (grades 1 and 2) without any other abnormal uronephric findings was noted in 105 infants $(0.88 \%)$. Thomas et al. [10] have argued that an anterior-posterior diameter of the renal pelvis of less than $12 \mathrm{~mm}$ (grades 1 and 2) is hardly of any clinical importance and should be neglected unless the dilatation involves the calices. Causes for temporary or incidential dilatation of $<12 \mathrm{~mm}$ are previous oral fluid supply [11] or a full urinary bladder of the newborn [12]. Particularly in preterm infants, a temporary dilatation of the renal pelvis can also be caused by immaturity of the ureteropelvic or ureterovesical junction in combination with an increase in urine production [13]. While we cannot comment on the therapeutic consequences of RPE grades 1 and 2 based on our purely diagnostic-epidemiologic study, we did note a correlation between RPE grade and the duration of gestation. In our study, pre- (vs full) term infants born between the 31st and 37th gestational week showed significantly $(\mathrm{p}=0.003)$ more often lower grade RPE (grades 1 and 2). In contrast, RPE grade 4 was seen significantly more often in infants with a birth weight over $4.000 \mathrm{~g}(\mathrm{p}=0.041)$ and in infants whose mothers had been diagnosed with gestational diabetes mellitus ( $<$ 0.001). Smaller cohort screening studies by Dremsek et al. [14], Yeung et al. [15] and Hiraoka et al. [16], showed a predisposition of the male gender and a predominance of left-sided obstructive uropathies. These results are now confirmed in our larger screening study.

In our and other [7,17] studies, ureteropelvic obstruction was the most common cause for dilatation of the renal pyelon (57\%). Underlying mechanisms include compression of the ureter due to a segmental renal artery; narrowing of the ureteral lumen due to fibroid degeneration of the ureteropelvic transition-zone secondary to regression of the embryonic renal vessels; damage of the urothelium due to migration and degranulation of mastocytes with ejection of histamine and prostaglandin resulting in a prolonged muscular spasm; an increased mobility of the kidney in relation to the ureter, leading to an intermittent snap in the region of the ureteropelvic junction; temporary vesicoureteral reflux without specific anatomical abnormalities $[1,7,18,19]$. Interestingly, we found RPE grades 2-4 without structural changes in the urinary tract in $12 \%$ of our newborn infants with sonographic dilatation of calices. Obviously, RPE is not always associated with structural changes.

The incidence of anomalies in renal position and parenchyma in our patient population is similar to that reported in other studies [5,20,21] (Figure 1). Like in our study, anomalies in renal position with morphological and functional changes of the ureter were significantly more often associated with dilatation of the renal pyelon [1].

Tsai et al. [20], Tsuchiya et al. [21], and Peters et al. [22] showed in prospective sonographic studies that newborn-screening of urinary tract anomalies is useful because it leads to early treatment. Ureteropelvic obstruction can remain clinically inconspicous over a long time period and cause hydronephrosis only in later 
childhood, adolescence and adulthood [23]. Therefore, Ismaili et al. [23] concluded that only sonographic screening with initiation of timely therapy can effectively prevent hydronephrosis with loss of kidney function. Tsai et al. [20] recommended that urosonography be carried out within the first days of life and, if indicated, that appropriate treatment be initiated as early as possible. Prophylaxis against urinary tract infections, further diagnostic imaging, interventional or surgical corrections can then be planned in a timely manner.

The major limitation of our diagnostic-epidemiologic study is the lack of, and correlation with, long-term follow-up. However, in a study by Tsuchiya et al. [21] most of the infants with ureteropelvic obstruction did not need any surgical correction. In a thorough follow-up study, spontaneous remission of a great number of obstructions were documented. However, in cases of ongoing obstruction, surgical correction should be planned as soon as possible [24]. Chertin et al. [25] and Ulman et al. [26] have shown that early surgical correction of an ureteropelvic obstruction leads to remarkable improvement in renal function.

\section{CONCLUSION}

Sonographic screening of the kidneys and the urinary tract early after birth, as shown in our large cohort over a 10 -year period, is an effective and non-invasive method to diagnose RPE in early postnatal life. Standardization of renal pelvis dilatation by means of perimetric quantification of pyelectasis may optimize the use of appropriate follow-up studies and timely therapeutic procedures, and may improve the prognosis of mechanical and functional obstructive uropathies.

\section{REFERENCES}

[1] Carrera, J.M., Torrents, M., Mortera, C., Cusi, V. and Munoz, A. (1995) Routine prenatal ultrasound screening for fetal abnormalities: 22 years' experience. Ultrasound in Obstetrics \& Gynecology, 5, 174-179. doi:10.1046/j.1469-0705.1995.05030174.x

[2] Hiraoka, M., Hori, C., Tsukahara, H., Kasuka, K., Ishihara, Y., Kotsuji, F. and Mayumi, M. (1999) Vesicoureteral reflux in male and female neonates as detected by voiding ultrasonography. Kidney International, 55, 14861490. doi:10.1046/j.1523-1755.1999.00380.x

[3] Palmer, L.S., Maiselz, M., Cartwright, P., Fernbach, S.K. and Conway, J.J. (1998) Surgery versus observation for managing obstructive grade 3 to 4 unilateral hydronephrosis: A report from the Society for Fetal Urology. The Journal of Urology, 159, 222-228. doi:10.1016/S0022-5347(01)64072-2

[4] Fasolato, V., Poloniato, A., Bianchi, C., Spagnolo, D., Valsecchi, L., Ferrari, A., Paesano, P. and Del Maschio, A. (1998) Feto-neonatal ultrasonography to detect renal abnormalities. American Journal of Perinatology, 15, 161-164. doi:10.1055/s-2007-993918

[5] Anderson, N.G., Abbott, G.D., Mogridge, N., Allan, R.B., Meling, T.M. and Wells, J.E. (1997) Vesicoureteric reflux in the newborn: Relationship to fetal renal pelvic diameter. Pediatric Nephrology, 11, 610-616. doi:10.1007/s004670050348

[6] Fanos, V., Agostiniani, R. and Cataldi, L. (2000) Pyelectasis and hydronephrosis in the newborn and infant. Acta Paediatrica, 89, 900-904. doi:10.1111/j.1651-2227.2000.tb00404.x

[7] Park, J.M. and Bloom, D.A. (1998) The pathophysiology of UPJ obstruction: Current concepts. The Urologic Clinics of North America, 25, 161-169. doi:10.1016/S0094-0143(05)70004-5

[8] Fernbach, S.K., Maizels, M. and Conway, J.J. (1993) Ultrasound grading of hydronephrosis: Introduction to the system used by the Society for Fetal Urology. Pediatric Radiology, 23, 478-480. doi:10.1007/BF02012459

[9] Blane, C.E., DiPietro, M.A., Strouse, P.J., Koo, H.P. and Bloom, D.A. (2003) Pediatric renal pelvic fullness: An ultrasonographic dilemma. The Journal of Urology, 170, 201-203. doi:10.1097/01.ju.0000065246.62888.c0

[10] Thomas, D.F., Madden, N.P., Irving, H.C. and Arthur, R.J. (1994) Mild dilatation of the fetal kidney: A follow-up study. British Journal of Urology, 74, 236-239. doi:10.1111/j.1464-410X.1994.tb16593.X

[11] Wong, D.C., Anderson, P.A., Macken, M. and Jackson, J.R. (1999) Congenital hydronephrosis who requires intervention? Canadian Journal of Urology, 6, 812-818.

[12] Schuster, W. (1990) Kinderradiologie 2. Springer-Verlag, Berlin, 611-653.

[13] Chudleigh, T. (2001) Mild pyelectasis. Prenatal Diagnosis, 21, 936-941. doi:10.1002/pd.204

[14] Dremsek, P.A., Gindl, K., Voitl, P., Strobl, R., Hafner, E. and Geissler, W. (1997) RPE in fetuses and neonates: Diagnostic value of renal pelvis diameter in pre- and post-natal sonographic screening. American Journal of Roentgenology, 168, 1017-1019.

[15] Yeung, C.K., Godley, M.L., Dhillon, H.K., Gordon, I, Duffy, P.G. and Ransley, P.G. (1997) The characteristics of primary vesico-ureteric reflux in male and female infants with prenatal hydronephrosis. British Journal of Urology, 80, 319-327. doi:10.1046/j.1464-410X.1997.00309.x

[16] Hiraoka, M., Morikawa, K., Hori, C., Tsuchida, S., Kasuga, K. and Tominaga, T. (1995) Left renal pelvis of male neonates is predisposed to dilatation. Acta Paediatrica Japan, 37, 352-354.

[17] Yoshida, J., Tsuchiya, M., Tatsuma, N. and Murakami, M. (2003) Mass screening for early detection of congenital kidney and urinary tract abnormalities. Pediatrics International, 5, 142-149. doi:10.1046/j.1442-200X.2003.01681.X

[18] Bartoli, F.A., Paradies, G., Leggio, A., Virgintino, D., Bertossi, M. and Roncali, L. (1996) Urothelium damage as the primary cause of ureteropelvic junction obstruction. Urological Research, 24, 9-13.

doi:10.1007/BF00296726 
[19] Kapadia, H., Lidefelt, K.J., Erasmie, U. and Pilo, C. (2004) Antenatal renal pelvis dilatation emphasizing vesicoureteric reflux: Two-year follow-up of minor postnatal dilatation. Acta Paediatr, 93, 336-339. doi:10.1111/j.1651-2227.2004.tb02957.x

[20] Tsai, J.D., Huang, F.U. and Tsai, T.C. (1998) Asymptomatic vesicoureteral reflux detected by neonatal ultrasonographic screening. Pediatric Nephrology, 12, 206209. doi:10.1007/s004670050438

[21] Tsuchiya, M., Hayashida, M., Yanagihara, T., Yoshida, J., Takeda, S., Tatsuma, T.H., Hino, Y., Munakata, E. and Murakami, M. (2003) Ultrasound screening for renal and urinary tract anomalies in healthy infants. Pediatrics International, 45, 617-623. doi:10.1046/j.1442-200X.2003.01780.x

[22] Peters, C.A. (1995) Urinary tract obstruction in children. The Journal of Urology, 154, 1874-1883. doi:10.1016/S0022-5347(01)66815-0

[23] Ismaili, K., Avni, F.E., Martin, W.K., Hall, M. and Brus- sels Free University Perinatal Nephrology Study Group (2004) Long-term clinical outcome of infants with mild and moderate fetal pyelectasis: validation of neonatal ultrasound as a screening tool to detect significant nephrouropathies. The Journal of Pediatrics, 144, 759-765.

[24] Koff, S.A. (1998) Neonatal management of unilateral hydronephrosis: Role for delayed intervention. Urologic Clinics of North America, 25, 181. doi:10.1016/S0094-0143(05)70006-9

[25] Chertin, B., Friedmans, A., Knizhnik, M., Hadas-Halperin, I., Hain, D. and Farkas, A. (1999) Does early detection of ureteropelvic junction obstruction improve surgical outcome in terms of renal function? The Journal of Urology, 162, 1037-1040. doi:10.1016/S0022-5347(01)68058-3

[26] Ulman, I., Jayanthi, V.R. and Koff, S.A. (2000) The longterm follow up of newborns with severe unilateral hydronephrosis initially treated nonoperatively. The Journal of Urology, 164, 1101-1105. doi:10.1016/S0022-5347(05)67262-X 